
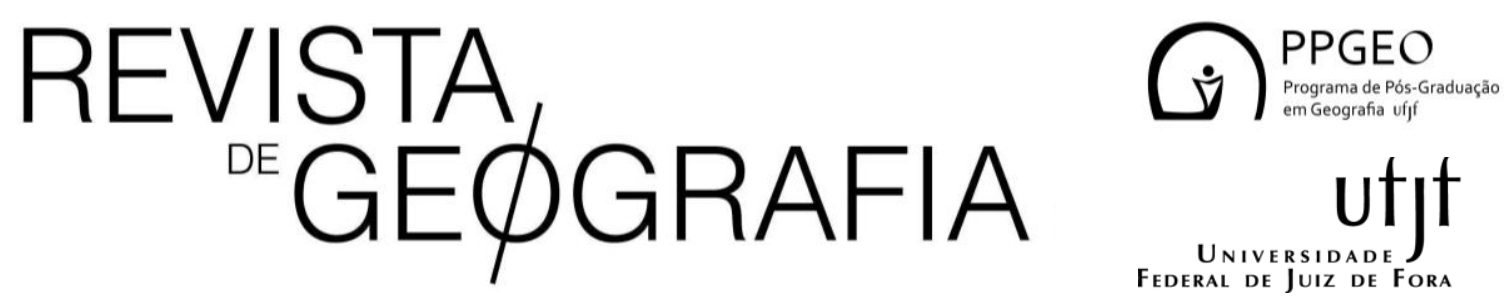

\title{
IMPACTO VISUAL DE EMPREENDIMENTO EÓLICO NA PAISAGEM DO CERRO DO JARAU POR MEIO DE SIMULAÇÃO DIGITAL
}

\author{
VISUAL IMPACT OF A WINDFARM ON THE LANDSCAPE OF CERRO DO JARAU THROUGH \\ DIGITAL SIMULATION
}

João Gabriel Junqueira Ribeiro Universidade Federal do Rio Grande do Sul (UFRGS) Av. Bento Gonçalves, 9500 - 91501-970 - Porto Alegre - RS - Brasil E-mail: junqueira.ribeiro@ufrgs.br

Tanice Cristina Kormann Fundação Estadual de Proteção Ambiental Henrique Luiz Roessler (FEPAM) Av. Borges de Medeiros 261 - 90020-021 - Porto Alegre - RS - Brasil E-mail: tanice.kormann@gmail.com

Roberto Verdum Universidade Federal do Rio Grande do Sul (UFRGS) Av. Bento Gonçalves, 9500 - 91501-970 - Porto Alegre - RS - Brasil

E-mail: verdum@ufrgs.br

\section{Resumo}


No presente trabalho busca-se apresentar contribuições da simulação digital à análise da paisagem no processo de licenciamento ambiental. Trata-se de um estudo de caso no entorno do Cerro do Jarau, patrimônio geológico e cultural do Estado do Rio Grande do Sul, onde tramita o licenciamento de um empreendimento eólico. Tendose a paisagem como categoria de análise geográfica, se considera esta tanto como uma marca quanto uma matriz. Assim, para se avaliar os possíveis impactos na paisagem, quanto à instalação do empreendimento, objetivou-se realizar simulações no software Windplanner, permitindo a inserção dos aerogeradores em fotografias panorâmicas. Considerou-se o critério de distância de $5 \mathrm{~km}$ de afastamento, visando diminuir o grau de impacto visual na paisagem. As simulações auxiliam na avaliação dos impactos ambientais decorrentes da implementação de empreendimentos eólicos, permitindo uma melhor visualização da futura paisagem, por parte dos analistas e da comunidade em geral.

Palavras-chave: paisagem, geração de energia eólica, Avaliação de Impacto Ambiental (AIA), licenciamento ambiental, Cerro do Jarau.

\section{Abstract}

The present work seeks to present contributions from digital simulation to landscape analysis in the environmental licensing process. This is a case study in the surroundings of Cerro do Jarau, geological and cultural heritage of the State of Rio Grande do Sul, where the licensing of a wind farm is being processed. Having the landscape as a category of geographic analysis, it is considered both as a mark and as a matrix. Thus, to evaluate the possible impacts on the landscape, regarding the installation of the project, the objective was to carry out simulations using the Windplanner software, allowing the insertion of the wind turbines in panoramic photographs. Was considered the distance criteria of $5 \mathrm{~km}$, aiming to reduce the degree of visual impact on the landscape. The simulations assist in the evaluation of the environmental impacts resulting from the implementation of wind projects, allowing a better visualization of the future landscape, by analysts and the community in general. 
Keywords: landscape, wind power generation, environmental impact assessment (EIA), environmental licensing, Cerro do Jarau.

\section{Introdução}

A expansão da atividade de geração de energia por fonte eólica, diante do desenvolvimento tecnológico, tem se refletido na ampliação dos parques eólicos em áreas potencialmente produtivas no território nacional. Neste contexto, novas regiões têm sido requeridas para a implantação de empreendimentos eólicos no Estado do Rio Grande do Sul, sendo o caso do Pampa.

O licenciamento da atividade é realizado pelo órgão estadual de licenciamento ambiental, que adota os critérios estabelecidos pela Portaria FEPAM № 118/2014. Esta Portaria define as "Diretrizes para Licenciamento de Empreendimentos Eólicos no Estado do Rio Grande do Sul", resultado do cruzamento de estudos multidisciplinares que integraram análises de temas do meio físico, biótico e socioeconômico.

Dentre os estudos que resultaram nestas diretrizes, o tema da paisagem foi inserido devido à necessidade de valoração das paisagens de interesse, por parte da população residente e transeunte, no entorno das áreas potenciais para a instalação dos empreendimentos eólicos. A valoração das paisagens foi estabelecida de 1 (um) a 5 (cinco), sendo que o valor 1 (um) foi atribuído às paisagens reconhecidas como de baixo interesse de referência (identidade) pelos entrevistados, enquanto o valor 5 (cinco) foi atribuído às paisagens consideradas de referência pelos entrevistados. Estas informações foram espacializadas, resultando em um mapa-síntese, conforme pode ser visualizado na Figura 1.

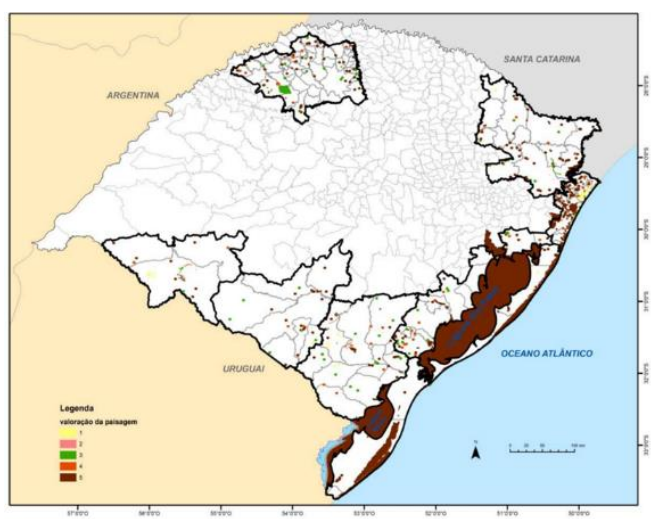

Figura 1: Mapa indicando os pontos relativos à paisagem e as respectivas valorações. 
Diante da existência de processos de licenciamento ambiental de empreendimentos eólicos, nas proximidades ou mesmo em locais de paisagens consideradas de máxima valoração, faz-se necessário o estabelecimento de critérios, visando minimizar o impacto negativo na paisagem. Para tanto, no presente trabalho se propõe apresentar os critérios que vêm sendo adotados para minimizar o impacto negativo na paisagem, diante do licenciamento ambiental de empreendimentos de geração de energia eólica, instalados nestas paisagens de máxima valoração no Pampa.

\section{2. Área de Estudo}

Trata-se de um estudo de caso em área requerida para licenciamento junto à paisagem de máxima valoração no Pampa, o Cerro do Jarau, situado no município de Quaraí, sudoeste do estado (Figura 2). Neste local, os elementos ou conjuntos da paisagem identificados como patrimônios culturais, individuais ou coletivos, são considerados de valor 5 (cinco), ou seja, de máxima valoração para a paisagem, pelos residentes no seu entorno e turistas que o visitam. Desta forma, a paisagem do Cerro do Jarau é lembrada por indivíduos e coletivos como sendo aquela em que as pessoas se identificam significativamente, atribuindo o sentido de pertencimento. $O$ local é considerado ícone de referência paisagística para a população gaúcha, por ser palco de uma das mais famosas lendas sul-rio-grandenses, recolhida e transcrita da tradição oral para a literatura por Simões Lopes Neto em "Salamanca do Jarau". Assim, a região, e o cerro em especial, possuem importância no contexto histórico e cultural, visto que o Cerro do Jarau é cercado de misticismo e folclore.

Além disso, a singularidade desta paisagem está relacionada aos aspectos geológicos e geomorfológicos, que têm relação com a morfogênese desta elevação. Lisboa et al. (1988) e Crósta e Lourenço (2010) apontam que a gênese do Cerro do Jarau está associada ao impacto de um meteorito (astroblema) que resultou numa cadeia de morros em formato semicircular, com elevação que passa dos 150 metros em relação às áreas do entorno. Tal impacto resultou em uma complexidade litológica a partir da exposição de litologias areníticas em uma região onde predominam as rochas vulcânicas, além da presença de material vitrificado, originado a partir do impacto. 
O Cerro do Jarau está localizado nas margens da rodovia RS-377, possibilitando ao observador que transita nesta rodovia, em qualquer sentido, avistálo desde seu acostamento, permitindo uma melhor visualização e contemplação da paisagem. As características descritas se refletem na ocorrência de uma paisagem que se torna ponto de atração visual pelo seu caráter de unicidade das formas, ao qual são atrelados valores culturais, históricos e científicos, tornando o Cerro do Jarau como um ícone na paisagem da Campanha gaúcha.

A Figura 2 ilustra a localização do cerro, no contexto regional, destacando-se a rede rodoviária e hidrográfica, assim como a sua localização em zona de fronteira Brasil - Uruguai:
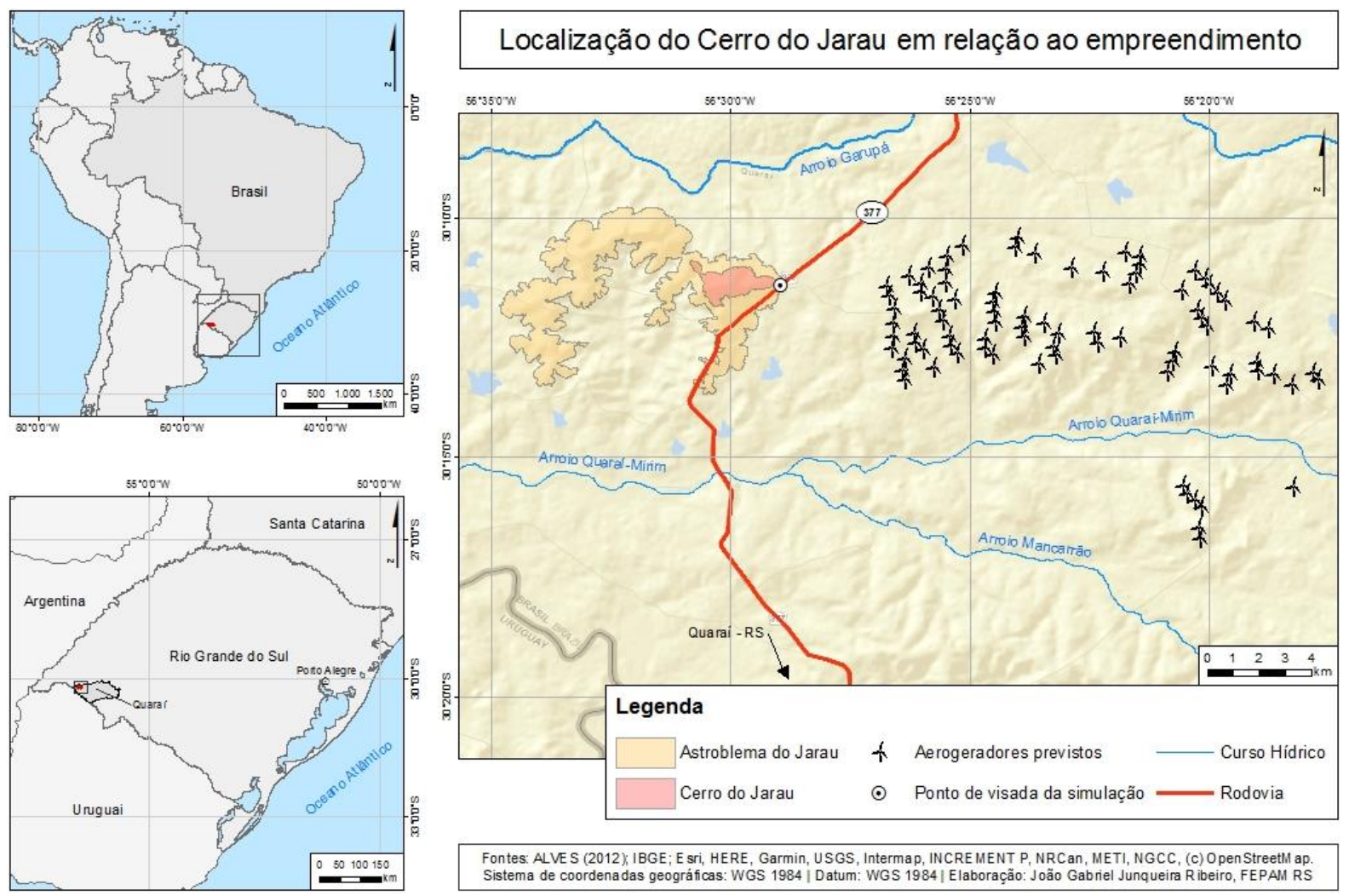

Fontes: ALVE S (2012), IBGE; E Eri, HERE, Garmin, USGS, Intermap, INCRE MENT P, NRCan, METI, NGCC, (c) Open StreetM ap.
Sistema de coordena das geográficas: WGS 1984 | Datum: WGS 1984 | Elaboração: João Gabriel Junqueira Ribeiro, FEPAM RS

Figura 2: Mapa de localização do Cerro do Jarau, com destaque ao empreendimento a ser licenciado.

Constituindo-se numa exceção na paisagem regional, onde predominam os campos com relevo suavemente ondulado, denominados regionalmente como coxilhas, o cerro também é dotado de significativa relevância ecológica. A complexidade no âmbito geológico e geomorfológico resulta na importância do local para a manutenção da biodiversidade regional. Alves (2012) aponta que a variação no relevo originou uma diversidade de ambientes que, por sua vez, se traduz no 
aumento da biodiversidade local, indicada pela ocorrência de 64 espécies vegetais endêmicas, raras e/ou ameaçadas.

A biodiversidade, portanto, tem estreita relação com a geodiversidade encontrada no Cerro do Jarau. Assim, o local se configura num excelente exemplo da abordagem integrada visto que tanto esta geodiversidade quanto a biodiversidade constituem suporte material para que seja atribuída sua importância no contexto histórico e cultural. Por se tratar do ponto mais elevado da região, o Cerro do Jarau foi ponto estratégico nas batalhas pela demarcação das fronteiras entre Portugal e Espanha. Tal fato propiciou com que o local se tornasse palco de lendas de fundamental importância para a cultura gaúcha, tornando-o uma paisagem de referência para a comunidade. Todos estes elementos fazem com que, na atualidade, o local venha sendo objeto de estudo para pesquisas científicas e culturais das mais diversas áreas do conhecimento.

A singularidade do Cerro do Jarau é descrita por diversos autores. Rambo (1956, p.145), já cita o Cerro do Jarau e sua importância paisagística:

A campanha é um oceano, não de água, mas de grama. Esta impressão é reforçada pela Coxilha do Jarau no extremo sul da paisagem. Levantando-se do meio dum colar de vegetação mais alta, graminácea, quase branca como a espuma da ressaca, seus cerros brilham ao sol como ilhotes de granito no mar. Mesmo de longe ressaltam as arestas de arenito metamórfico conglutinados neste serrote mais ocidental do Rio Grande do Sul, figurando monstros petrificados de eras que já vão longe.

Além do contexto de qualificação morfológica que o destaca na paisagem do Pampa, Vieira (2014, p.199) aponta que a beleza cênica do Cerro do Jarau é caracterizada por diversas falas de pesquisadores que estudam a região, em diferentes temáticas:

"pelo contraste na paisagem, ao enxergá-lo." "[...] é uma forma de relevo que se diferencia da planura dos campos. Traz aos moradores uma dimensão da natureza diferenciada. Possui uma expressão cultural, local de histórias, lendas e filmes". "[...] pela presença de espécies ornamentais, pela vista da paisagem do entorno e pelo manejo tradicional de rebanhos pelo gaúcho". "[...] por sua morfologia imponente, sua composição ecológica e suas referências históricas que, inclusive, o tornaram ícone cultural regional". "[...] pela rara beleza, pelos ambientes prístinos, espécies endêmicas/raras, entre outros". 
Em contraste com o valor intrínseco desta paisagem, quanto aos seus aspectos de identidade e beleza cênica, tem-se a instalação dos complexos eólicos, com seus aerogeradores que costumam ultrapassar os $90 \mathrm{~m}$ de altura em espaços ora elevados ora amplos, aproveitando o potencial eólico disponível para a geração de energia. Consequentemente, com potencial de serem avistados a uma grande distância e interferirem nas paisagens de referência de moradores do entorno e transeuntes.

A singularidade do cerro, contrastante às coxilhas e planícies do entorno, pode ser observada na Figura 3:

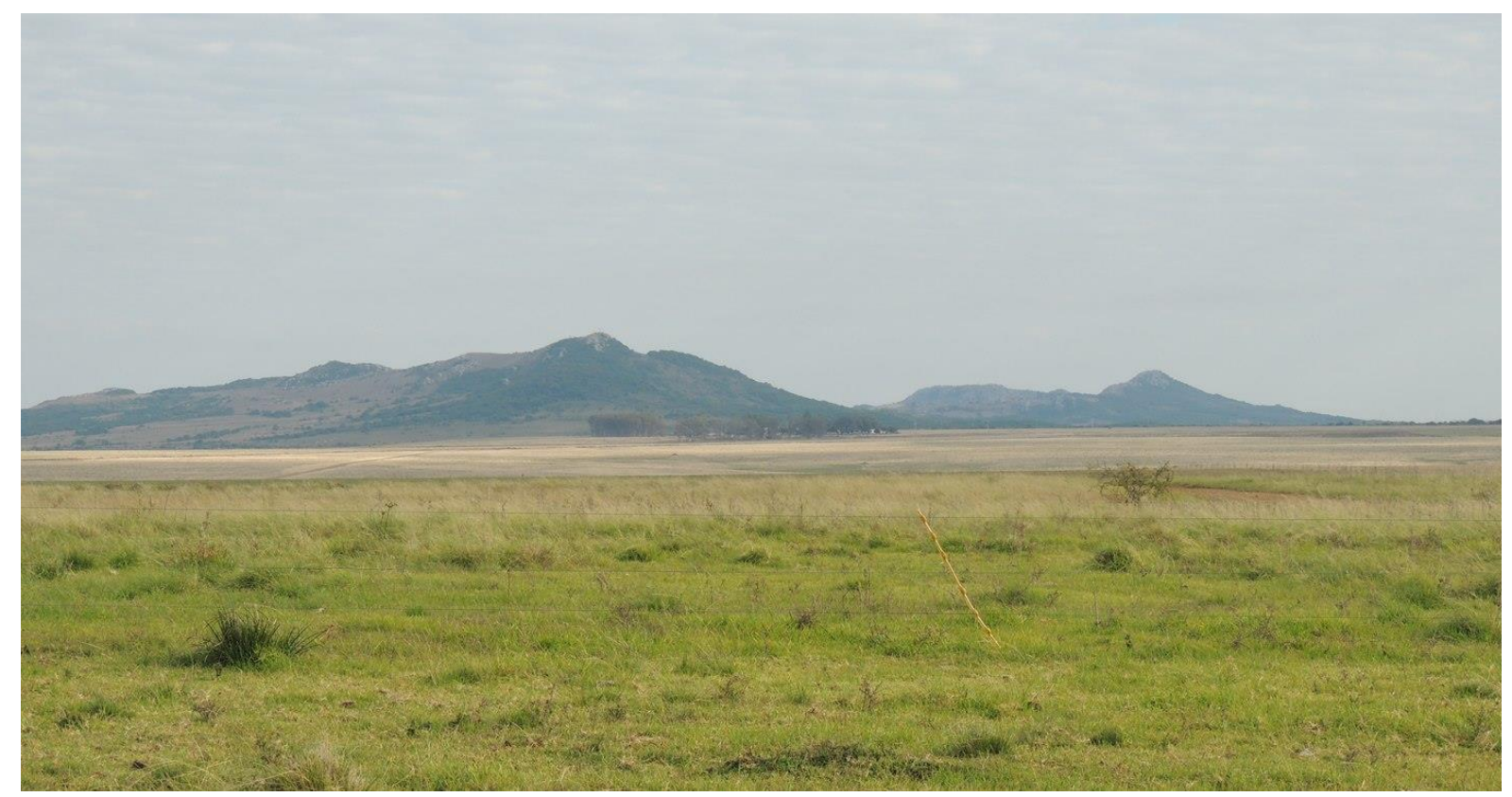

Figura 3: Vista para o Cerro do Jarau desde a área proposta para o empreendimento.

\section{Metodologia}

Em um contexto de franca expansão do setor energético brasileiro nos últimos anos, como forma de responder à crise de energia ocorrida no Brasil em 2001, a energia eólica é a fonte cujo crescimento foi o mais significativo (BIER E VERDUM, 2014). Entretanto, a efetivação desta fonte como alternativa energética evidencia a existência de impactos socioambientais, decorrentes da instalação dos diversos complexos eólicos (BRANNSTROM et al., 2019). 
No cenário riograndense, a portaria $n^{\circ}$ 118/2014 da FEPAM traz em suas Diretrizes a paisagem como um dos critérios de análise, pois incorporou a valoração de pontos de interesse paisagístico do Estado. Diante da existência de processos de licenciamento ambiental de empreendimentos eólicos nas proximidades de paisagens consideradas de máxima valoração, a presente pesquisa buscou apresentar métodos que vêm sendo utilizados para contribuir no estabelecimento de critérios visando minimizar o impacto na paisagem.

O uso da paisagem enquanto categoria de análise permite compreender as relações e transformações entre sociedade e natureza (BIER E VERDUM, 2014). Assim, no presente estudo, a paisagem foi concebida a partir da paisagem perceptiva para a realização do inventário dos pontos de interesse paisagístico. Esta abordagem analisa a paisagem simultaneamente como marca, refletindo a relação de uma sociedade com a natureza, e ao mesmo tempo como matriz, visto que participa da construção do sistema de representação que molda o olhar dos indivíduos e grupos humanos em um determinado lugar e tempo (VERDUM, 2012). Parte-se primeiramente da descrição da paisagem percebida, avistada com o olhar, porém ao se alterar a escala espacial ou temporal, ultrapassa-se o campo do visual. Enquanto matriz, esta paisagem carrega um caráter subjetivo, já que leva em conta a percepção, seja esta individual ou coletiva (BIER E VERDUM, 2014).

Segundo Katsaprakakis (2012), em boas condições meteorológicas e sem barreiras físicas, uma turbina eólica pode ser avistada a uma distância de 400 vezes em relação à medida de sua altura. Deste modo, com o aumento da distância entre o observador e o aerogerador, o impacto visual do equipamento tende a ser suavizado, no contexto perceptivo, como se houvesse uma gradativa incorporação das turbinas à paisagem local (KATSAPRAKAKIS, 2012). Partindo disto, o autor se baseia ainda na publicação PAN 45 (2002), elaborada pelo Governo Escocês, onde este estabelece medidas de distância que retratam a percepção em relação aos aerogeradores, localizados em áreas abertas, como forma de auxiliar no planejamento para a instalação de empreendimentos eólicos. Tais referências métricas estão expressas na Tabela 1: 


\begin{tabular}{ll}
\hline Distância & Percepção \\
\hline até $2 \mathrm{~km}$ & Feição proeminente na paisagem \\
$2 \sim 5 \mathrm{~km}$ & Feição relativamente proeminente na paisagem \\
$5 \sim 15 \mathrm{~km}$ & Visto como parte da paisagem num contexto geral \\
$15 \sim 30 \mathrm{~km}$ & Visto como um elemento secundário na paisagem (avistado \\
& somente em boas condições meteorológicas) \\
\hline
\end{tabular}

Figura 4: Tabela 1 - Relação da distância do parque eólico com a percepção humana na paisagem

Fonte: Pan 45 (Revised 2002): Renewable Energy Technologies

Estes critérios de distância passaram a ser considerados nos processos de licenciamento ambiental que tramitam na FEPAM, a fim de minimizar os impactos na paisagem diante da implantação de empreendimentos eólicos no estado. Apesar da existência destes critérios avaliativos, cada processo de licenciamento acaba exigindo uma análise contextual individual, pelas particularidades locacionais e de projeto, o que tem sido suprido por meio de simulações, sendo esta considerada como uma segunda etapa metodológica.

Siefert e Santos (2016), sugerem que, para se obter uma avaliação mais precisa dos impactos deve-se considerar, ainda, o ângulo de visada do observador.Para este fim, nesta pesquisa buscou-se avaliar a aplicação da distância de $5 \mathrm{~km}$ por meio da utilização de uma ferramenta que simula a nova paisagem com a inserção das estruturas (turbinas eólicas) em funcionamento.

Para a realização das simulações utilizaram-se os dados existentes no projeto do empreendimento eólico, tais como o posicionamento e o modelo das turbinas, que definem a sua altura. A partir destes dados, na avaliação utilizou-se o software Windplanner, que realiza a inserção das turbinas em fotos panorâmicas em um ambiente tridimensional, a partir de fotografias panorâmicas do Google Street View e imagens de satélite do Google Earth. Esta integração resulta em um produto que se assemelha a uma fotografia da área de estudo, permitindo avaliar visualmente o possível arranjo paisagístico com o parque eólico em operação.

O software propicia uma utilização bastante prática e direta, permitindo a realização de imagens 2D, 3D e em 360 graus. Ele ainda proporciona a execução de simulações em vídeo, utilizando como base as fotografias panorâmicas do Google 
Street View ou as imagens de satélite do Google Earth. Os resultados podem ser apresentados de forma online ou através da exportação das imagens realizadas. Para realizar a exportação, no entanto, o usuário necessita de um segundo software, dedicado à captura de vídeo. No caso das simulações realizadas no curso desta pesquisa, utilizou-se o software OBS Studio como ferramenta complementar, o qual permite a captura de qualquer área da tela do computador.

\section{Resultados e discussões}

Considerando que o Cerro do Jarau é mencionado na Portaria FEPAM № 118/2014 como local impróprio para licenciamento de empreendimentos eólicos e que há o interesse na conservação do mesmo, pois tramita de um processo de criação de Unidade de Conservação no local, no presente estudo de caso busca-se apresentar os procedimentos e critérios técnicos que vêm sendo utilizados para evitar o impacto negativo na paisagem, diante da proposição de empreendimento eólico lindeiro a paisagens de máxima relevância para o povo gaúcho. Para assegurar que o empreendimento eólico não seja mais proeminente que o Cerro do Jarau, se propôs a distância de $5 \mathrm{~km}$ do ponto culminante da elevação como critério para afastamento, a partir do qual as estruturas poderiam ser posicionadas. A Figura 4 representa uma simulação realizada para a área em questão, com o layout dos aerogeradores dispostos a uma distância de $5 \mathrm{~km}$ do Cerro do Jarau.

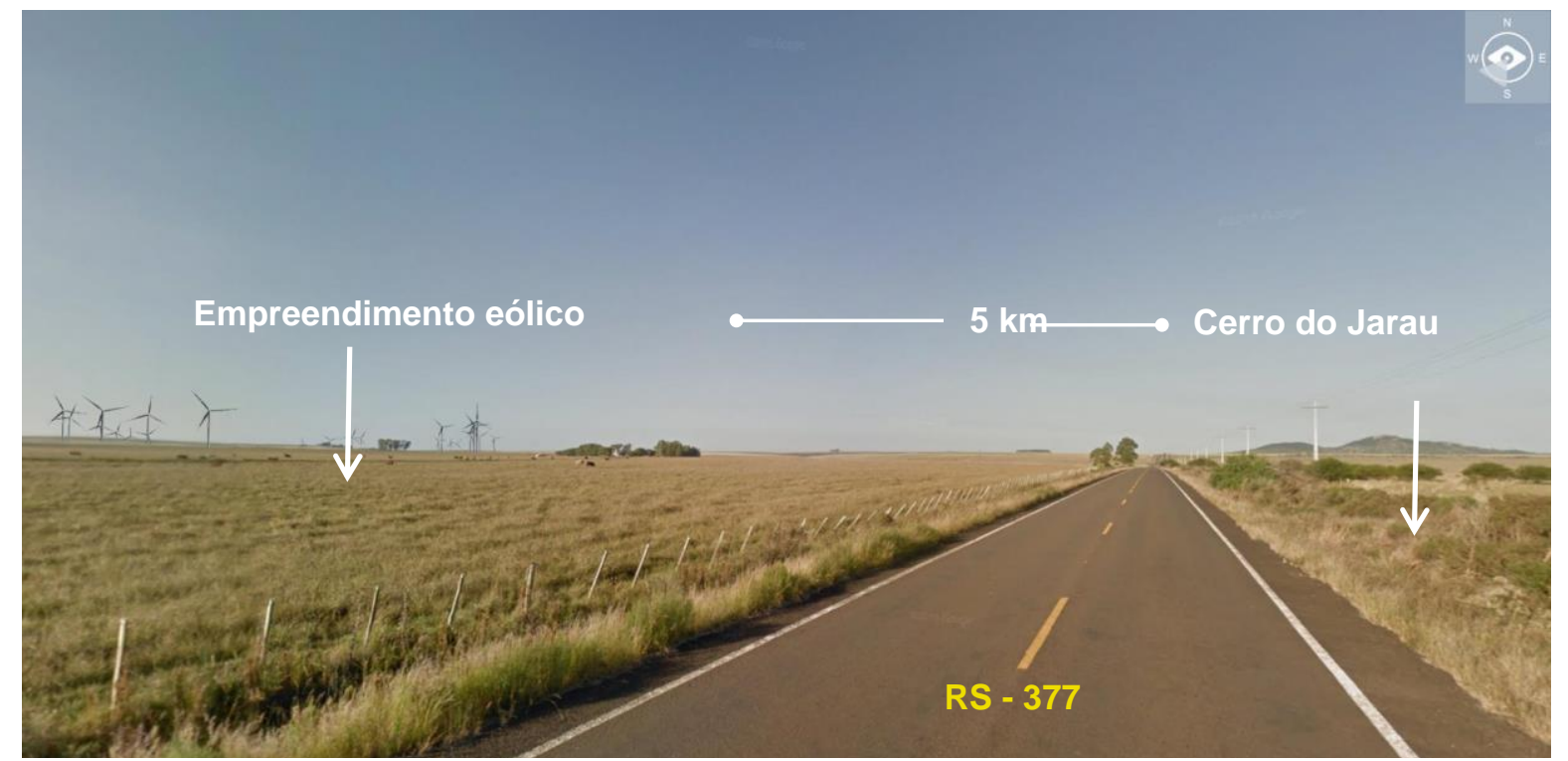

Figura 5: Exemplo de simulação, onde o Cerro do Jarau aparece à direita da RS-377, considerando um observador que transita no sentido NE-SW. 


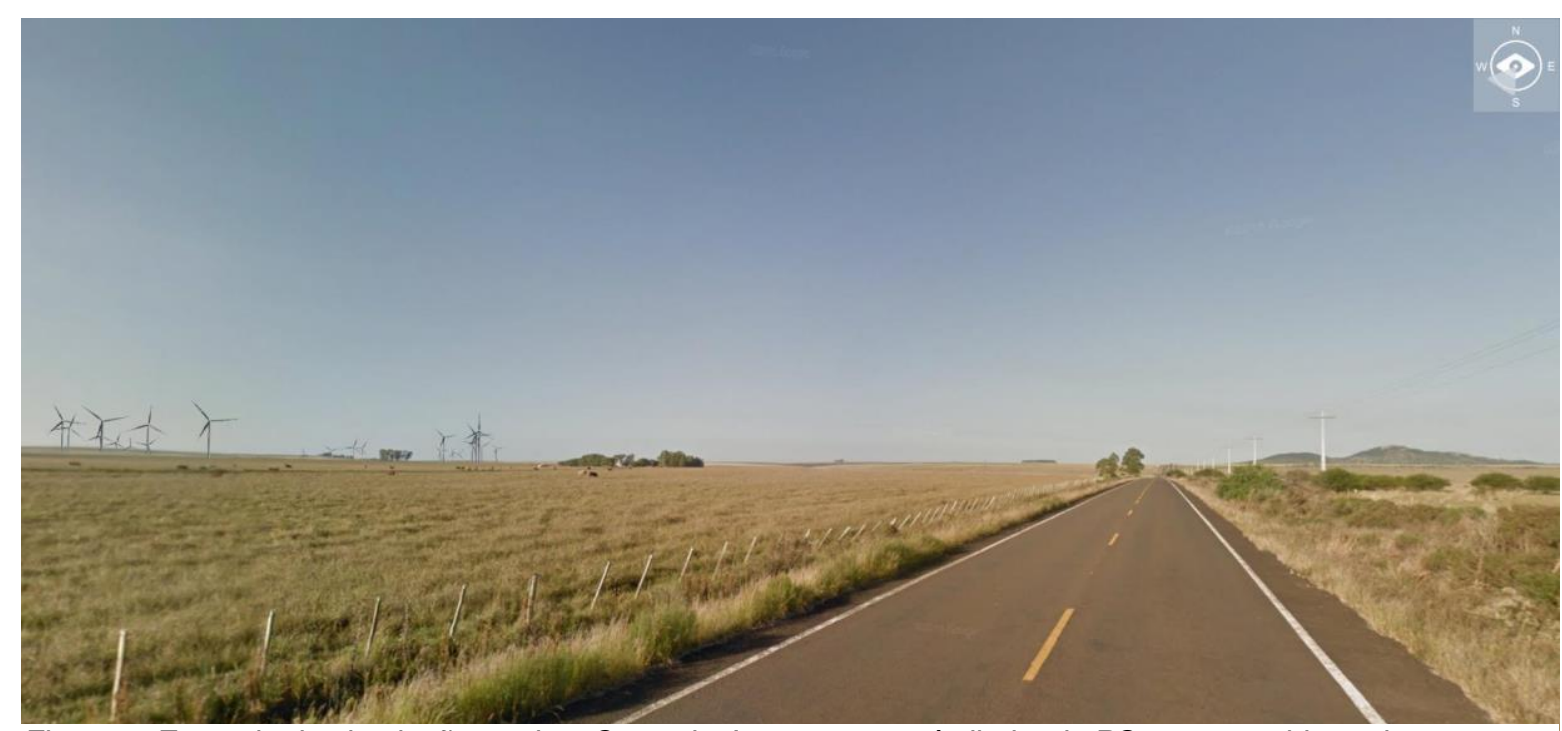

Figura 4: Exemplo de simulação, onde o Cerro do Jarau aparece à direita da RS-377, considerando um observador que transita no sentido NE-SW.

Fonte: Elaborada pelos autores no Software Windplanner

Analisando a figura, percebe-se que o local proposto para o empreendimento está localizado na margem oposta da RS-377, em relação ao Cerro do Jarau. Assim, para quem transita na rodovia, não haverá o bloqueio do plano de visada para o Cerro, independente se trafegando no sentido norte-sul ou sul-norte. A Figura 3, ainda mostra que o Cerro do Jarau e o empreendimento eólico comporão espaços paisagísticos distintos e, desta forma, a vista do geopatrimônio se distingue da paisagem que será transformada pela presença do parque eólico, sobretudo, em função do contexto geral da visada ser separado pela rodovia RS-377.

Tal proposição permitiu diminuir o grau de impacto do empreendimento eólico, fazendo com que tanto o Cerro do Jarau quanto o empreendimento eólico ficassem afastados do observador quando este estiver posicionado na rodovia RS-377 que cruza a região (principal estrada de acesso). Assim, tanto as elevações que compõe o Cerro do Jarau quanto os aerogeradores do empreendimento eólico estariam posicionados a cerca de 2,5 $\mathrm{km}$ do local de visada do observador. Desta forma, a percepção do impacto ambiental do empreendimento passa a ser positiva, já que poderia tornar o local mais atrativo turisticamente sem que a proeminência do Cerro do Jarau fosse afetada.

Além da inserção dos aerogeradores na foto panorâmica do Google Street View, o software também permite elaborar simulações para diferentes horários do dia. Esta ferramenta insere os aerogeradores em uma imagem de satélite do Google Earth e altera as condições de iluminação da imagem, simulando sua diferença durante o 
dia e a noite. Neste caso, o ponto de visada passa a ser descolado do solo, podendo variar conforme o interesse do usuário. Um comparativo entre a presença das turbinas em três horários do dia, isto é, à tarde, pela manhã e à noite, ser observado na Figura 5.

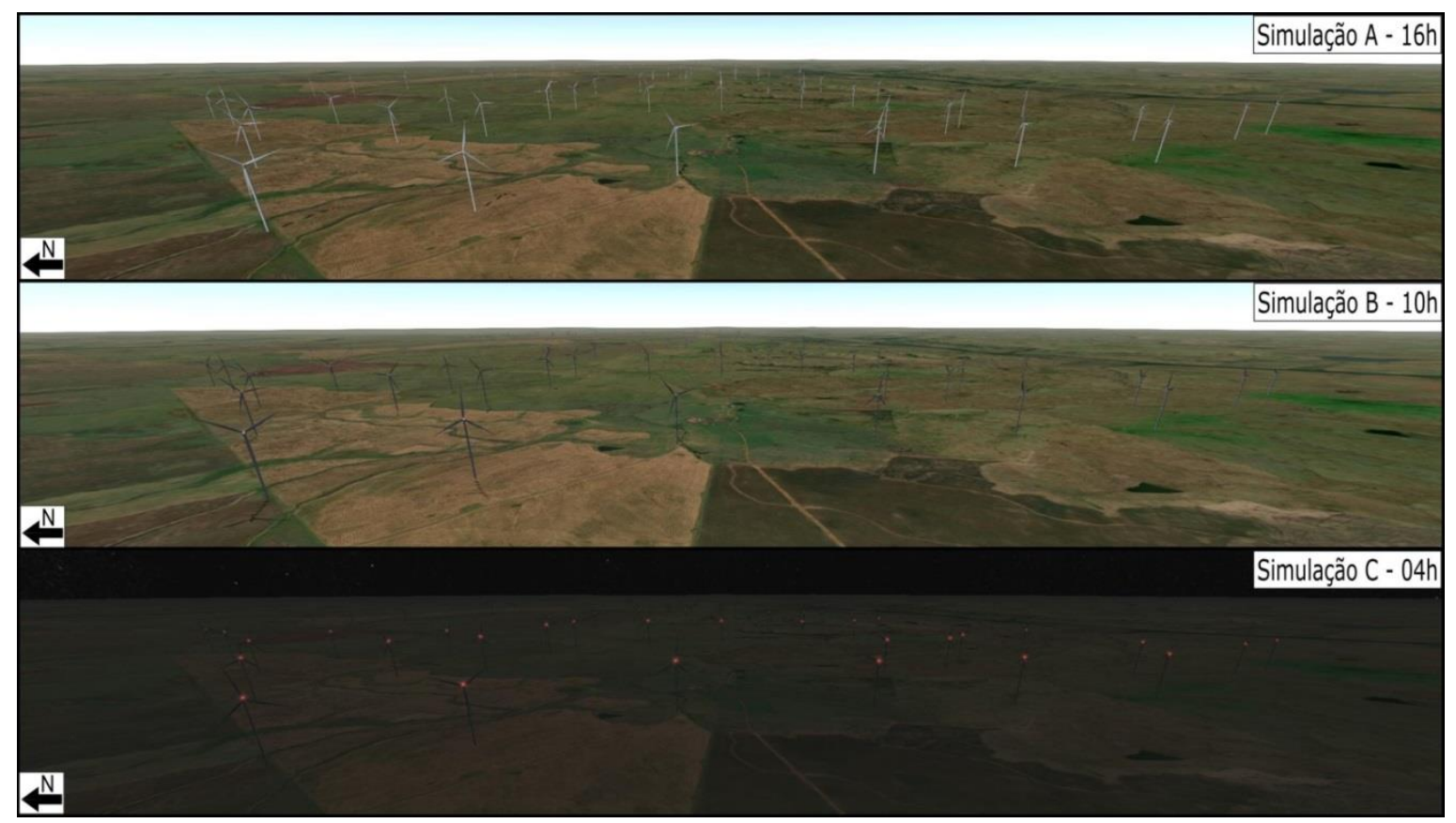

Figura 6Comparativo entre diferentes horários do dia e as condições de iluminação e visibilidade das turbinas. Fonte: Elaborada pelos autores a partir de simulações do Software Windplanner

A Figura 5 permite considerar que a diferença de luminosidade ao longo do dia interfere na percepção visual do aerogerador. Além disto, destaca-se a influência visual das estruturas também à noite, pois elas apresentam uma luz de sinalização vermelha piscante. Neste sentido, estas simulações contribuem para melhor dimensionar os tipos de impacto visual e assim ter um prognóstico futuro da paisagem.

Deste modo, as simulações obtidas com a utilização do software Windplanner permitiram dar suporte à decisão por parte dos analistas ambientais, além de permitir que a comunidade local, quando consultada durante o processo de licenciamento ambiental, tivesse uma percepção visual mais próxima da realidade quanto às mudanças que ocorrerão na paisagem, quando da implantação do empreendimento. Para além deste suporte, é possível considerar que a aplicação do método que leva em conta a distância como principal fator de diminuição do impacto visual, sendo combinada à ferramenta de simulação visual, permite qualificar a análise do impacto 
do empreendimento na paisagem, qualificando assim o processo de licenciamento como um todo.

\section{Considerações Finais}

A utilização do software Windplanner possibilitou a execução de simulações, utilizando fotos panorâmicas, imagens de satélite e simulações em vídeo. Este procedimento permitiu uma análise mais realista dos possíveis impactos negativos causados ao patrimônio geomorfológico, cultural e paisagístico, na perspectiva da percepção visual da paisagem. Sobretudo, em relação aos patrimônios paisagísticos ou de interesse cênico, como é o caso do Cerro do Jarau e demais referências paisagísticas no Pampa.

Consideram-se positivos os resultados obtidos com a aplicação das referências teórico-metodológicas propostas e aplicadas por Katsaprakakis (2012) e Siefert e Santos (2016) na área de estudo em questão. Conciliadas às ferramentas digitais de simulação foi possível avaliar tecnicamente os potenciais impactos da inserção dos aerogeradores na paisagem. Destaca-se a relevância do trabalho em um contexto no qual, ainda, são reduzidas as pesquisas que propõem metodologias com a perspectiva de dar suporte ao licenciamento ambiental no âmbito dos órgãos públicos.

O processo em questão se mostrou um excelente estudo de caso, permitindo o avanço em direção à consolidação do uso da distância como critério metodológico e da elaboração de simulações que permitem melhor avaliar os impactos futuros com a implantação de empreendimentos eólicos no contexto de paisagens de relevância. Sendo assim, acredita-se estar contribuindo para a qualificação do processo de licenciamento, sendo esta metodologia importante para conciliar o desenvolvimento dos setores econômicos com a preservação da qualidade ambiental para a presente e futuras gerações.

\section{Agradecimentos}

Agradecemos à Fundação de Amparo à Pesquisa do Estado do Rio Grande do Sul (FAPERGS) pela concessão da bolsa de pesquisa (Iniciação Científica), possibilitando a realização desta investigação junto à FEPAM. Agradecemos também 
à UFRGS, em especial ao Programa de Pós-Graduação em Geografia (POSGEA) do Instituto de Geociências (IGEO), pelo apoio técnico e pela coorientação durante o percurso desta pesquisa.

\section{Referências Bibliográficas}

ALVES, Fabiano da Silva. Fitogeografia da região do Jarau Quaraí/RS. Tese de Doutorado. PPG em Engenharia Florestal, Universidade Federal de Santa Maria, 2012.

BIER, Lucile Lopes; VERDUM, Roberto. Percepção da Paisagem: Aerogeradores em Tapes (RS). Espaço Aberto, v. 4, n. 1, p. 47-64, 2014.

BRANNSTROM, Christian et al. Processos políticos e impactos socioambientais da energia eólica no litoral cearense. In: GORAYEB, Adryane; BRANNSTROM, Christian; MEIRELES, Antônio (orgs). Impactos socioambientais da implantação dos parques de energia eólica no Brasil, p. 25. Fortaleza: Edições UFC, 2019.

CRÓSTA, Alvaro P.; LOURENÇO, Fernanda Silva; PRIEBE, Gustavo Heinzelmann. Cerro do Jarau, Rio Grande do Sul: A possible new impact structure in southern Brazil. Geological Society of America Special Papers, v. 465, p. 173-190, 2010.

EXECUTIVE, Scottish. Planning Advice Note 45: Renewable Energy Technologies. Edimburgo, Reino Unido, 2002. Disponível em http://www. scotland. gov. uk/Publications/2002/02/pan45/pan-45. Acesso em 10 de janeiro de 2020.

KATSAPRAKAKIS, Dimitris AI. A review of the environmental and human impacts from wind parks. A case study for the Prefecture of Lasithi, Crete. Renewable and Sustainable Energy Reviews, v. 16, n. 5, p. 2850-2863. 2012.

LISBOA, Nelson. A. et al. Reconhecimento geológico da região do Jarau, Quaraí, RS. SBG, Simpósio Sul Brasileiro de Geologia, v. 3, p. 319-332, 1987.

RAMBO, Balduíno. A Fisionomia do Rio Grande do Sul. São Leopoldo: Editora Unisinos, 3ํㅡㄹ 1956.

RIO GRANDE DO SUL. Fundação Estadual de Proteção Ambiental Henrique Luiz Roessler. Portaria no 118, de 01 de dezembro de 2014. Dispõe acerca da regulamentação do art. 3ำ da resolução CONAMA 462/2014 e estabelece os critérios, exigências e estudos prévios para o licenciamento ambiental de empreendimentos de geração de energia a partir da fonte eólica, no Estado do Rio Grande do Sul. Anexo II. Rio Grande do Sul, 2014

SIEFERT, Cesar Augusto Crovador; DOS SANTOS, Irani. Avaliação do impacto visual de parques eólicos na qualidade e estética da paisagem no entorno de áreas protegidas: estudo de caso do Parque Estadual do Guartelá, PR. Raega-O Espaço Geográfico em Análise, v. 38, p. 221-244, 2016. 
VERDUM, Roberto et al. Percepção da Paisagem na Instalação de Aerogeradores no Rio Grande do Sul. In: VERDUM et al. (orgs). Paisagem: leituras, significados e transformações. Porto Alegre: Editora da UFRGS, 2012.

VIEIRA, Lucimar de Fátima dos Santos. A valoração da beleza cênica da paisagem do bioma pampa do Rio Grande do Sul: proposição conceitual e metodológica. Tese de Doutorado. PPG em Geografia, Universidade Federal do Rio Grande do Sul, 2014. 